Баженова В. В., Шайхутдинова О. Р.

V. V. Bazhenova, O. R. Shaikhutdinova

ИСПОЛЬЗОВАНИЕ БУХГАЛТЕРСКИХ БАЛАНСОВ ДЛЯ ОЦЕНКИ ПЕРСПЕКТИВ ПРЕДПРИНИМАТЕЛЬСТВА

\title{
THE USE OF FINANCIAL STATEMENTS TO ASSESS THE PERSPECTIVES OF ENTREPRENEURSHIP
}

Баженова Виктория Викторовна - кандидат экономических наук, доцент кафедры экономики, финансов и бухгалтерского учета Комсомольского-на-Амуре государственного технического университета (Россия, Комсомольск-на-Амуре); 681013, г. Комсомольск-на-Амуре, пр. Ленина, 27; 8-962-296-83-02. E-mail: vitasyavitasya@yandex.ru.

Ms. Victoria V. Bazhenova - PhD in Economic Sciences, Associate Professor, Department of Economics, Finance and Accounting, Komsomolsk-on-Amur State Technical University (Russia, Komsomolsk-on-Amur); 681013, Komsomolsk-on-Amur, Lenin str., 27; 8-962-296-83-02. E-mail: vitasyavitasya@yandex.ru.

Шайхутдинова Ольга Раисовна - магистр Комсомольского-на-Амуре государственного технического университета (Россия, Комсомольск-на-Амуре); 681013, г. Комсомольск-на-Амуре, пр. Ленина, 27. E-mail: barbie6629@mail.ru.

Ms. Olga R. Shaikhutdinova - master's degree student major in Economic Sciences, Komsomolsk-on-Amur state technical University (Russia, Komsomolsk-on-Amur); 681013, Komsomolsk-on-Amur, Lenin str., 27. E-mail: barbie6629@mail.ru.

Аннотация. Статья посвящена изучению эффективности движения капитала в производственной системе на основе бухгалтерского баланса.

Summary. The article is devoted to studying the efficiency of capital flow in the production system on the basis of the balance sheet.

Ключевые слова: капитал предприятия, повышение производительной силы труда, балансоведение, бухгалтерский баланс, потенциал бизнеса.

Key words: enterprise capital, increasing productive forces of labor, the balance science, the balance sheet, the potential of the business.

УДК 330

Структурно капитал предприятия подразделяется на основной и оборотный. Финансовые потоки, составляя наиболее ликвидную часть оборотного капитала и выполняя жизнеобеспечивающую функцию, разветвляются в сторону выполнения внутренних и внешних обязательств предприятия. В финансовых потоках отражается интенсивность движения оборотного капитала, которая генерируется повышением производительной силы труда. При ускорении оборачиваемости, при каждом дополнительном кругообороте оборотных средств за счет повышения производительной силы предприятие получает дополнительный доход в виде прибыли с начислением амортизации основных средств. При этом экономическая суть амортизационных отчислений сводится не столько к возмещению износа, сколько к возврату капитальных вложений от эксплуатации основных фондов предприятия.

Эффективность движения капитала в производственной системе исследуется фундаментально разработанными методами финансового анализа. Структурные характеристики капитала в бухгалтерском балансе дают представление о результативности повышения производительной силы труда за данный период, где прибыль и заемный капитал выступают как главные факторы структурных изменений. Исследование динамики использования капитала решает многочисленные задачи, в том числе связанные с выяснением условий равновесного имущественного состоя- 
ния предприятия, условий его финансовой устойчивости. Основная информация для исследований принимается из стандартного бухгалтерского баланса с использованием инструментария балансоведения и составлением как первичных, так и вторичных бухгалтерских балансов. Первые - статистические балансовые отчеты - составляются в соответствии с действующим законодательством и разработанными на этой основе стандартами и инструктивно-методическими указаниями. Вторые производные балансы с определенным целевым назначением - составляются с некоторыми видоизменениями, упрощениями и допущениями путем трансформации первичных статистических балансовых отчетов. Такого рода балансы в финансовом анализе могут применяться для оценки экономического потенциала предприятия, для выяснения адаптивных качеств бизнеса при использовании производительной силы труда персонала. Структура капитала в этих балансах характеризует как рыночные, так и производственные возможности предпринимательства - деловой потенциал.

В дополнение к экономической диагностике как распознаванию жизнеспособности предприятия с позиций повышения производительной силы труда можно отнести самостоятельную область знаний:

- изучающую природу капитала предприятия;

- исследующую капитал при взаимоотношениях предпринимателя как с рынком, так и с трудовым коллективом, включая как благоприятные, так и неблагоприятные моменты, с которыми предприниматель входит непосредственно в контакт;

- распознающую роль и преимущества капитала данного предприятия в сложных конкурентных взаимоотношениях, определяющих условия борьбы за выживание.

При этом некоторые методы балансоведения мы рассматриваем как один из инструментариев экономической диагностики.

Не акцентируя внимание на данной области знаний, авторы курса «балансоведение» и другие исследователи капитала, подчеркивая значимость учета потенциальных возможностей предпринимательской деятельности, принимают их в основу при выяснении сущности потенциала предприятия. Но, формируя методологию оценки потенциала предприятия, следует отметить, что в бухгалтерском балансе отражается отчетная информация, которая не раскрывает реально существующих скрытых потенциальных возможностей предпринимательской деятельности. Так, «скромные возможности» бухгалтерского баланса в отражении динамических явлений экономики, принимаемых для финансового анализа, отмечают многие исследователи, в том числе и профессор А. П. Латкин: «Подобный подход, по нашему мнению, представляется несколько упрощенным, а данные, полученные на его основе, не вполне корректными, поскольку информация бухгалтерского баланса дает весьма приблизительную характеристику финансового состояния предприятия. Это связано с тем, что бухгалтерская отчетность, в том числе баланс, составляется с определенной периодичностью и является «фотографией» состояния на определенную дату. Следовательно, рассчитанные на его основе показатели также приблизительно характеризуют финансовое состояние предприятия» $[1,76]$.

Недостаток данных в бухгалтерском балансе для выяснения потенциала предприятия подтверждает и приводимая авторами балансоведения цитата профессора Питера Друкера «потенщиал бизнеса всегда выле реализованной действительности», которая свидетельствует о фиксировании уже случившихся структурных изменениях капитала и оставшихся непознанными скрытых от учета потенциальных возможностях предпринимателя. Дело в том, что динамика финансовых процессов и факторы, способствующие процветанию бизнеса, в отчетной информации конкретно не раскрываются $[2,258]$. В нашем представлении непредсказуемость бизнеса заключается в том, что при любом росте объемов работ, их рентабельности можно дополнительно выявить непредвиденные возможности повышения эффективности использования ресурсов предприятия. Отсюда и реализованная действительность, представляя только часть использованных производственных возможностей, не может на 100 \% раскрыть производственный потенциал предприятия. Это как раз и подтверждает профессор П. Друкер в приведенной выше цитате. Развитие предприятия можно связать с постоянно определяемой вероятностной оценкой его производственных возможностей и их интенсивным использованием. 
Баженова В. В., Шайхутдинова О. Р.

ИСПОЛЬЗОВАНИЕ БУХГАЛТЕРСКИХ БАЛАНСОВ ДЛЯ ОЦЕНКИ ПЕРСПЕКТИВ ПРЕДПРИНИМАТЕЛЬСТВА

Основываясь на приведенных высказываниях в составе основополагающих принципов диагностического подхода к распознаванию потенциала бизнеса на организационно-прикладном уровне, можно представить принцип превышения потенциальных возможностей (потенциала) над реальной действительностью (достигнутым объемом производства).

Отсюда можно сделать вывод, к которому приходят многие исследователи, что потенциал любого предприятия равен сумме достигнутого объема продукции (работ, услуг) плюс неиспользованные возможности роста объемов производства.

Капитал в бухгалтерском балансе можно рассматривать как количественную характеристику ресурса, потенциально используемого для производственных целей. Ресурсная характеристика капитала присутствует при трактовке активов бухгалтерского баланса во многих зарубежных странах (США, Франции, Голландии и др.).

Ресурсное представление капитала непосредственно связано с характеристикой имущественного положения предприятия. Так, В. В. Ковалев финансовую оценку имущественного (в нашем понимании - ресурсного) потенциала предприятия представляет активом баланса предприятия, а также данными в приложениях к основной отчетности. В курсе балансоведения стоимость предприятия обосновывается определением его «общего потенциала». При этом потенциал организации представляет ее реальную или вероятную способность выполнить целенаправленную работу [3].

Авторский коллектив во главе с доктором экономических наук, профессором Н. А. Бреславцевой, а также авторы других изданий наделяют капитал таким, в какой-то степени органическим свойством, как способность [3]. Но следует отметить, что данное качество, на наш взгляд, может применяться для характеристики трудового коллектива, в использовании которого находится производственный капитал, который и характеризует производительную силу труда. Все структурные изменения производственного капитала в результате его движения в основном зависят от усилий трудового коллектива, от его способности интенсивно использовать потенциал производственной деятельности. Можно согласиться с тем, что активы и источники образования активов характеризуют, в частности в балансоведении, ресурсный потенциал. Но производственные возможности его использования целиком зависят от активности трудового коллектива, от эффективности использования ресурсов во времени. Только такая способность труда может принести в бизнесе доход при осуществлении производственно-финансовой деятельности. В балансоведении, игнорируя эту активность персонала, представляют данную категорию «действующим потенциалом». Определенные финансовые результаты при этом принимаются во внимание для оценки «общего потенциала предприятия», представляющего его стоимость. Потенциал с позиций его энергетической сущности, т.е. запасенной потенциальной энергии, можно рассматривать, с одной стороны, как ресурс, а с другой, принимая во внимание активность использования этого ресурса как потенциальную силу воздействия этого ресурса в производстве продукции.

Принимая во внимание математическую модель производительной силы капитала $F=m \times a$, ее ресурсная составляющая может быть представлена как $m$ - масса капитала, а воздействие или активность ресурса - это $a$ - ускорение наращения капитала. Ресурсный потенциал как $m$ - масса капитала с позиций его использования в бухгалтерском балансе представляется активами. Активы, находящиеся в собственности предприятия (включая имущественные права), можно назвать ядром такого ресурсного потенциала. Собственные активы, характеризуя финансовую обеспеченность кредита, обусловливают возможности, связанные с источниками образования других активов, за счет которых можно увеличить капитал предприятия. В основном такие перспективные устремления связываются с наращением объема производства, реинвестированием прибыли и другими источниками наращения капитала. В данной интерпретации потенциал, как и структура капитала, характеризуется в статике. Для стоимостной характеристики ресурсного потенциала используются «Стандарты оценки, обязательные к применению субъектами оценочной деятельности» (утверждены Постановлением Правительства Российской Федерации от 6 июля 2001 г. № 519). Для выявления его возможной активности анализируется и изучается будущее изменение структуры капитала, обусловленное потенциалом деловой активности персонала. При этом количественная оценка активности производится на базе статических бухгалтерских балансов. 
С позиций инвестиционного анализа активность использования капитала определяется внутренней нормой доходности и определением чистого дисконтированного дохода. Так, при возникновении предприятия в основе формирования его собственного капитала лежит уставный капитал (УК). Его величина, как правило, обосновывается инвестиционным проектом с возникающими денежными потоками от использования производственного капитала. Согласно действующим методическим разработкам по оценке эффективности инвестиционных проектов, принимается во внимание система показателей, характеризующих движение капитала. При выявлении «общего потенциала предприятия〉 следовало бы также учитывать эти показатели, в том числе временную стоимость денежного потока с дисконтированием будущих доходов и в сопоставлении с используемыми разновременными капитальными вложениями. В этом случае УК может приниматься за отправную базу отсчета прироста ресурсной части потенциала предприятия.

Ссылаясь на разработки В. В. Ковалева и других экономистов, можно считать, что важнейшим показателем, характеризующим ресурсный потенциал предприятия, является показатель чистых активов или показатель собственного капитала (СЧА - стоимость имущества и имущественные права). Этот показатель учитывает прирост собственности в стоимостном выражении, когда стоимость чистых пассивов превышает УК (СЧП > УК), либо величину потерь собственников в результате неэффективного использования собственности (СЧП < УК). Показатель чистых активов, учитывая наращение капитала, служит одним из основных показателей благополучия предприятия. Для коммерческих организаций размер чистых активов свидетельствует об их экономическом состоянии. Как известно, в соответствии с действующим в России законодательством величина чистых активов подсчитывается вычитанием из общей суммы активов суммы ее обязательств, принимаемых к расчету.

Используемое в экономическом анализе понятие «имущественного потенциала» предприятия численно определяется чистыми активами, которые характеризуют его имущественное положение - реальное богатство. При таком подходе учитывается и то, что какая-то часть имущества предприятия может быть отдана под залог. Прирост «имущественного потенциала» при стоимостной оценке имущества предприятия обусловливается приращением капитала за счет реинвестирования прибыли, а также дополнительными вкладами собственников фирмы, привлечением новых собственников, временным привлечением средств, безвозмездными поступлениями, целевыми поступлениями, переоценкой основных фондов.

При диагностике (распознавании) изменений структуры капитала по данным баланса, как и в экономическом анализе, необходимо соблюдать сопоставимость сравниваемых величин во времени. Сопоставимость обеспечивается переоценкой основных фондов по их восстановительной стоимости. При переоценке исторические цены «сглаживаются» и более объективно отражают количественную величину внеооборотных активов в их вещественном виде.

Проблеме определения собственности как финансового ресурса производственной деятельности посвящены многочисленные работы отечественных и зарубежных ученых. Как правило, в основу оценки и анализа собственности, а также процессов, связанных с управлением ею на действующем предприятии, принимается концепция создания (сохранения) стоимости (ценности) предприятия. Профессор Роберт Холт (Вирджинский Университет - США) отмечает два основополагающих принципа этой концепции: «повышение ценности фирмы» и «важность комплексного анализа при принятии финансовых решений» $[3,299]$. Поскольку собственность может быть количественно оценена и представлена с помощью стоимостных показателей, то используют три основных концептуальных подхода к оценке стоимости предприятия: имущественный или затратный, рыночный или сравнительный и доходный.

Считается, что оценка стоимости предприятия по балансовой структуре капитала - это первый обобщающий уровень стоимостной оценки его ресурсного потенциала. Чистая балансовая стоимость (ЧБС) предприятия характеризуется так же, как «чистая стоимость имущества», «собственный капитал», «стоимость чистых активов», «стоимость чистых пассивов». Для характеристики экономического потенциала предприятия некоторые авторы выделяют также показатель «действительной стоимости», под которым понимают только стоимость имущественного комплекса, генерирующего результаты хозяйственной деятельности. 
Баженова В. В., Шайхутдинова О. Р.

ИСПОЛЬЗОВАНИЕ БУХГАЛТЕРСКИХ БАЛАНСОВ ДЛЯ ОЦЕНКИ ПЕРСПЕКТИВ ПРЕДПРИНИМАТЕЛЬСТВА

Профессор А. П. Латкин, проведя анализ значительного количества опубликованных методик анализа имущества предприятия и выделив в их среде методику А. Д. Шеремета, Р. С. Сейфулина и Е. В. Негашева, пишет: «Однако, несмотря на ряд преимуществ, она также не учитывает всех особенностей экономического анализа в условиях развития рыночных отношений в нашей стране». Наиболее приемлемой профессор А. П. Латкин считает методику анализа финансового состояния О. В. Ефимовой, которая значительно расширяет рамки информационной базы, что, на его взгляд, «позволяет углубить и качественно улучшить сам финансовый анализ. Согласно этой методике, включающей в себя пять этапов, анализ баланса и рассчитанных на его основе коэффициентов, следует рассматривать в качестве предварительного этапа ознакомления с финансовым положением предприятия. В дальнейшем при анализе должны широко привлекаться данные аналитического и внутрипроизводственного учета» [1, 76-784].

При рыночном и доходном методе оценки предприятия используют стоимость чистых пассивов предприятия, т.е. величину активов, остающуюся в распоряжении предприятия после вычета всех обязательств. Используя рыночный подход к характеристике производственного потенциала предприятия, можно обратиться к уже имеющимся разработкам и положениям теории балансоведения. Так, профессор, доктор экономических наук И. Н. Богатая, формирующая положения эволюционно-адаптивного учета, считает, что при оценке потенциала предприятия следует рассматривать перспективы его развития на основе данных стратегического учета. Эволюционноадаптивный учет предполагает составление производных балансовых отчетов для целей принятия управленческих решений, направленных на развитие предприятия. В качестве инструментария для оценки возможностей развития предприятия предлагается использовать метод стратегических балансов. При этом, исходя из влияния внешних и внутренних факторов, составляют внешние и внутренние балансы. Цель внешних - выявление и измерение шансов и рисков предприятия на рынке (во внешней среде). Цель внутренних - выявление узких мест на предприятии путем определения сильных и слабых сторон направлений его деятельности. Данный подход можно рассматривать, на наш взгляд, как одно из направлений диагностики равновесного состояния предприятия. Однако баланс дает представление лишь о структурной характеристике капитала на определенный момент времени, не раскрывая потенциальных возможностей персонала предприятия. В какой-то степени характеристики активности персонала и потенциальные возможности капитала предприятия можно представить при составлении стратегических балансов. Для их составления, как утверждает И. Н. Богатая, чаще всего используются методики, основанные на балльной или процентной оценке сопоставления сфер деятельности предприятия. При этом устанавливаются различные внутренние нормативы или ограничения, определяющие момент наступления критического значения узкого места. Балансы могут строиться как в форме классической схемы баланса, так и в виде диаграммы в полярных координатах. При анализе балансов может производиться сопоставление стратегических балансов собственного предприятия и конкурентов.

Представляется важным выяснить, в какой степени методика построения балансов, используемая при финансовых прогнозах, способствует выяснению действительной величины потенциала предприятия. Дело в том, что в условиях рыночной экономики система балансовых отчетов считается основой финансового прогноза, анализа и управления. Но при этом особое значение приобретают производные балансы, которые считают неотъемлемой частью стратегического учета собственности.

Не подлежит сомнению, что бухгалтерская информация является важнейшим и основным источником для составления производных балансов и формирования модели оценки стоимости предприятия, а отсюда и его ресурсного потенциала. Но качество этой информации, используемой для этих целей, подлежит тщательной проверке.

\section{ЛИТЕРАТУРА}

1. Леонтьев, В. В. Межотраслевая экономика / В. В. Леонтьев; пер. с англ ; предисл. и науч. ред. А. Г. Гранберг. - М.: Экономика, 1997. - 479 с.

2. Белолипецкий, В. Г. Финансы фирмы: курс лекций / В. Г. Белолипецкий; под ред. И. П. Мерзлякова. М.: ИНФРА-М, 1999. - 298 с.

3. Балансоведение. Серия «Высшее образование». - Ростов н/Д.: Феникс, 2004. - 480 с. 